\title{
Effect of cold stress on heart rate and blood pressure in healthy offspring with and without parental history of type2 diabetes mellitus
}

\author{
Vivek P. ${ }^{1}$, Arifuddin M. K. ${ }^{2, *}$ \\ ${ }^{1}$ Assistant Professor, ${ }^{2}$ Assistant Professor, Dept. of Physiology, ${ }^{1}$ Chamarajanagar Institute of Medical Sciences, \\ Chamarajanagar, Karnataka, ${ }^{2}$ Sri Siddhartha Medical College, Tumkur, Karnataka, India \\ *Corresponding Author: \\ Email: drmkarifuddin786@gmail.com
}

Received: $07^{\text {th }}$ February, 2018

Accepted: $28^{\text {th }}$ February, 2018

\begin{abstract}
Introduction: The cold pressor test which is considered to be a sympatho-excitatory maneuver is a simple, noninvasive and validated test of sympathetic activation. The heart rate and blood pressure responses to CPT could be used as indicators of global sympathetic activation, and thus of cardiac status and autonomic function. Autonomic nervous system dysfunction at the subclinical level seems to be the predisposing condition that occurs far earlier before developing an overt diabetic condition.

Aims: To evaluate the cardiac autonomic status and its reactivity among healthy offspring with and without parental history of Type2 Diabetes Mellitus (T2DM). To Compare the autonomic reactivity by recording Heart Rate (HR) and Blood pressure during and after CPT between healthy offspring with and without parental history of T2DM.

Materials and Methods: This study consists of 40 healthy male subjects with family history of T2DM (cases) and 40 healthy male subjects without family history of T2DM (controls) in the age group of 18-25 years. HR and BP during and after CPT were compared between cases and controls.

Results: Student t test (two tailed, independent) has been used to find the significance of study parameters on continuous scale between two groups. HR response to post CPT showed significant differences between two groups across all the time points. Controls showed higher HR than cases at all the time points. However, the reduction of HR with time was more gradual in controls. The graphical representation of SBP changes after CPT, shows fluctuation among cases before it reaches the stable value, whereas, in controls the decrease was at constant level. Conclusion: The results suggest there was altered autonomic reactivity to physical stress among the offspring with parental history of T2DM when compared to their counterparts and hence this points towards the fact that they are at a risk of developing future autonomic dysfunction and cardiovascular complications.
\end{abstract}

Keywords: Cold Pressor test (CPT), Type2 Diabetes Mellitus (T2DM), Heart Rate (HR), Systolic Blood Pressure (SBP) and Diastolic Blood Pressure (DBP).

\section{Introduction}

Diabetes mellitus is a chronic metabolic disease characterized by hyperglycemia resulting from defects in insulin secretion, insulin action, or both. ${ }^{1}$ It has been shown that the prevalence of T2DM among offspring with one diabetic parent was $40 \%$, which increases to $80 \%$ if both parents are diabetic. ${ }^{2}$ A breakthrough study was done in which a genetic locus was confirmed and four other novel loci were identified which accounts for substantial portion of risk of development of T2DM. ${ }^{3}$ Therefore, genetic inheritance plays an important role in the pathogenesis of T2DM, thereby, increasing the susceptibility to develop the disease among individuals with strong family history of DM.

Autonomic nervous system (ANS) dysfunction at the subclinical level seems to be the predisposing condition that occurs far earlier before developing an overt diabetic condition. ${ }^{4,5}$ There is a rich ANS supply to major organs of glucose metabolism which includes liver, pancreas and skeletal muscles. ${ }^{6-8}$ Therefore ANS changes and metabolic alterations are linked to each other. Impaired autonomic activity may trigger hyperglycemia in non diabetic individuals. ${ }^{9}$ Studies have shown that autonomic dysfunction is often detected among the population even at the time of diagnosis of T2DM. ${ }^{5}$ This provides a hint that impaired autonomic activity might have developed even during normoglycemic stage.

\section{Materials and Methods}

This is a comparative study having total of 80 subjects - 40 Healthy male non diabetic subjects without parental history of T2DM, in the age group 1825 were included in the control group. 40 Healthy male non diabetic subjects with at least one parent with $\mathrm{T} 2 \mathrm{DM}$, in the age group 18-25 were included in the study group.

Subjects were selected among the general population and from the campus of Sri Siddhartha Medical College and Research Hospital, Tumkur. Ethical clearance of the protocol was obtained from "Ethical committee for human research" of Sri Siddhartha Medical College and Research hospital, Tumkur. Protocol was briefed to the subject and the informed written consent was obtained from all the subjects. 
Subjects with history of with Type I Diabetes Mellitus, those suffering from cardiac, respiratory, endocrine, metabolic, psychiatric and neurological diseases, those who are smokers or alcoholics or drug abusers, those on regular medications affecting cardiovascular and respiratory system, those undergoing any physical conditioning programme were excluded from the study.

\section{Experimental design: Cold Pressor Test}

Subject instructed to immerse the hand till the wrist in cold water $\left(1-4^{\circ} \mathrm{C}\right)$ for 2 minutes or until toleration whichever is earlier. Care was taken to ensure that the subject avoided any isometric contractions, breath holding or performance of Valsalva maneuver. HR, SBP and DBP using BPL cardiac monitor was obtained from the other arm at 30 seconds interval till subject removed the hand or completion of two minutes. After removing the hand the HR was recorded at an interval of 30 seconds for 3 minutes.

\section{Result}

Student t test (two tailed, independent) has been used to find the significance of study parameters on continuous scale between two groups on metric parameters. Chi-square/ Fisher Exact test has been used to find the significance of study parameters on categorical scale between two or more groups. The Statistical software namely SAS 9.2, SPSS 15.0, Stata 10.1 , were used for the analysis of the data. Significance is assessed at $5 \%$ level of significance.

Table 1: Comparison of age and anthropometric measurements between cases and controls

\begin{tabular}{|l|c|c|c|}
\hline \multicolumn{1}{|c|}{ Variables } & $\begin{array}{c}\text { Cases } \\
\mathbf{n = 4 0}\end{array}$ & $\begin{array}{c}\text { Controls } \\
\mathbf{n = 4 0}\end{array}$ & P value \\
\hline Age $($ years $)$ & $19.20 \pm 0.85$ & $19.05 \pm 0.78$ & 0.415 \\
\hline Height $(\mathrm{cm})$ & $1.71 \pm 0.07$ & $1.70 \pm 0.05$ & 0.594 \\
\hline Weight $(\mathrm{kg})$ & $61.10 \pm 8.29$ & $61.18 \pm 7.14$ & 0.966 \\
\hline BMI $\left(\mathrm{kg} / \mathrm{m}^{2}\right)$ & $20.88 \pm 2.61$ & $21.06 \pm 2.07$ & 0.739 \\
\hline Waist circumference $(\mathrm{cm})$ & $81.23 \pm 8.99$ & $79.98 \pm 5.95$ & 0.465 \\
\hline HIP circumference $(\mathrm{cm})$ & $94.58 \pm 8.89$ & $93.20 \pm 5.44$ & 0.407 \\
\hline W/H ratio & $0.86 \pm 0.03$ & $0.86 \pm 0.03$ & 0.953 \\
\hline Wrist circumference $(\mathrm{cm})$ & $16.4 \pm 0.78$ & $16.59 \pm 0.65$ & 0.245 \\
\hline
\end{tabular}

Table 2: Comparison of heart rate (bpm) during and after cold Pressor test (CPT) between cases and controls

\begin{tabular}{|l|c|c|c|}
\hline $\begin{array}{c}\text { Heart rate } \\
(\mathbf{b p m})\end{array}$ & $\begin{array}{c}\text { Cases } \\
(\mathbf{n = 4 0})\end{array}$ & $\begin{array}{c}\text { Controls } \\
(\mathbf{n = 4 0 )}\end{array}$ & P value \\
\hline Before - CPT & $74.40 \pm 8.02$ & $75.63 \pm 6.09$ & 0.444 \\
\hline During -CPT & & & \\
\hline 30 seconds & $78.70 \pm 7.33$ & $80.93 \pm 6.69$ & 0.160 \\
\hline 60 seconds & $81.35 \pm 8.44$ & $83.35 \pm 7.67$ & 0.271 \\
\hline After - CPT & & & \\
\hline 30 seconds & $72.43 \pm 7.62$ & $80.18 \pm 7.10$ & $<0.001^{* *}$ \\
\hline 60 seconds & $72.10 \pm 7.39$ & $78.80 \pm 6.72$ & $<0.001^{* *}$ \\
\hline 90 seconds & $72.50 \pm 5.77$ & $77.55 \pm 7.03$ & $<0.001^{* *}$ \\
\hline 120 seconds & $72.25 \pm 6.89$ & $76.63 \pm 6.45$ & $<0.001^{* *}$ \\
\hline 150 seconds & $71.25 \pm 8.91$ & $75.00 \pm 6.58$ & $<0.001^{* *}$ \\
\hline 180 seconds & $71.00 \pm 5.42$ & $74.18 \pm 6.11$ & $<0.001^{* *}$ \\
\hline
\end{tabular}

** Strongly significant ( $\mathrm{P}$ value: $\mathrm{P} \leq 0.01$ ) 
Graph 1: Comparison of Heart rate after CPT between cases and control

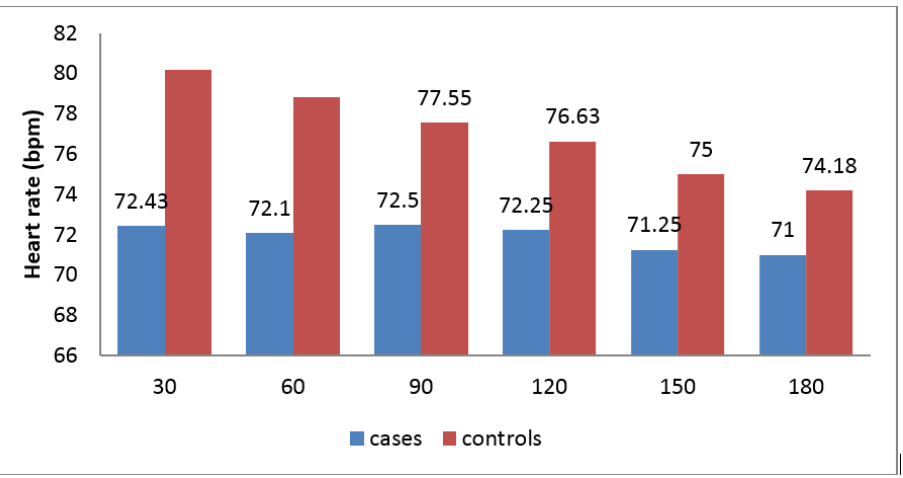

Table 3: Comparison of SBP ( $\mathrm{mm}$ of $\mathrm{Hg}$ ) during and after CPT between cases and controls

\begin{tabular}{|l|c|c|c|}
\hline $\begin{array}{c}\text { SBP } \\
(\mathbf{m m} \text { of Hg) }\end{array}$ & $\begin{array}{c}\text { Cases } \\
(\mathbf{n = 4 0})\end{array}$ & $\begin{array}{c}\text { Controls } \\
(\mathbf{n}=\mathbf{4 0})\end{array}$ & P value \\
\hline Before-CPT & $107.38 \pm 7.95$ & $105.78 \pm 7.02$ & 0.343 \\
\hline During -CPT & & & \\
\hline 30 seconds & $112.35 \pm 9.12$ & $110.55 \pm 7.64$ & 0.342 \\
\hline 60 seconds & $118.63 \pm 8.41$ & $117.18 \pm 7.61$ & 0.421 \\
\hline 90 seconds & - & - & - \\
\hline After-CPT & & & \\
\hline 30 seconds & $113.98 \pm 7.56$ & $113.35 \pm 7.93$ & 0.719 \\
\hline 60 seconds & $110.08 \pm 7.61$ & $109 \pm 7.68$ & 0.531 \\
\hline 90 seconds & $107.7 \pm 6.73$ & $107.85 \pm 7.39$ & 0.925 \\
\hline 120 seconds & $105.85 \pm 6.69$ & $106.6 \pm 7.17$ & 0.630 \\
\hline 150 seconds & $106.15 \pm 6.78$ & $105.2 \pm 6.53$ & 0.525 \\
\hline 180 seconds & $106.15 \pm 7.05$ & $104.4 \pm 6.44$ & 0.250 \\
\hline
\end{tabular}

Graph 2: Representation of SBP changes after CPT between cases and controls

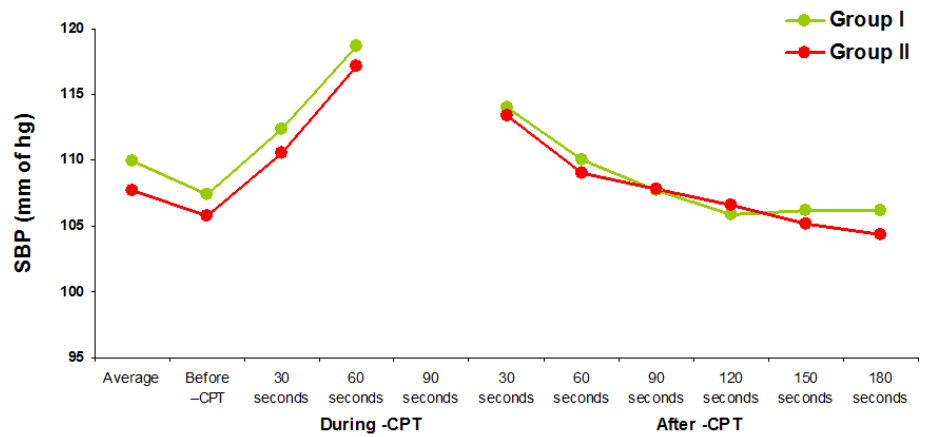

Table 4: Comparison of DBP ( $\mathrm{mm}$ of $\mathrm{Hg}$ ) during and after CPT between cases and controls

\begin{tabular}{|l|c|c|c|}
\hline $\begin{array}{c}\text { DBP } \\
(\mathbf{m m} \text { of } \mathbf{H g})\end{array}$ & $\begin{array}{c}\text { Cases } \\
(\mathbf{n = 4 0})\end{array}$ & $\begin{array}{c}\text { Controls } \\
(\mathbf{n = 4 0})\end{array}$ & P value \\
\hline Before - CPT & $67.83 \pm 7.91$ & $67.08 \pm 6.20$ & 0.638 \\
\hline During -CPT & & & \\
\hline 30 seconds & $73.78 \pm 6.76$ & $73.20 \pm 6.34$ & 0.696 \\
\hline 60 seconds & $79.48 \pm 9.05$ & $78.15 \pm 8.76$ & 0.508 \\
\hline 90 seconds & - & - & - \\
\hline After - CPT & & & \\
\hline 30 seconds & $73.23 \pm 7.17$ & $73.58 \pm 7.24$ & 0.829 \\
\hline 60 seconds & $69.58 \pm 7.73$ & $69.83 \pm 7.41$ & 0.883 \\
\hline 90 seconds & $68.65 \pm 7.74$ & $68.38 \pm 7.36$ & 0.871 \\
\hline 120 seconds & $66.83 \pm 7.35$ & $66.55 \pm 6.48$ & 0.860 \\
\hline 150 seconds & $66.1 \pm 6.72$ & $65.55 \pm 6.22$ & 0.705 \\
\hline 180 seconds & $65.63 \pm 6.75$ & $64.73 \pm 5.73$ & 0.522 \\
\hline
\end{tabular}




\section{Graph 3: Representation of DBP changes after CPT between cases and controls}

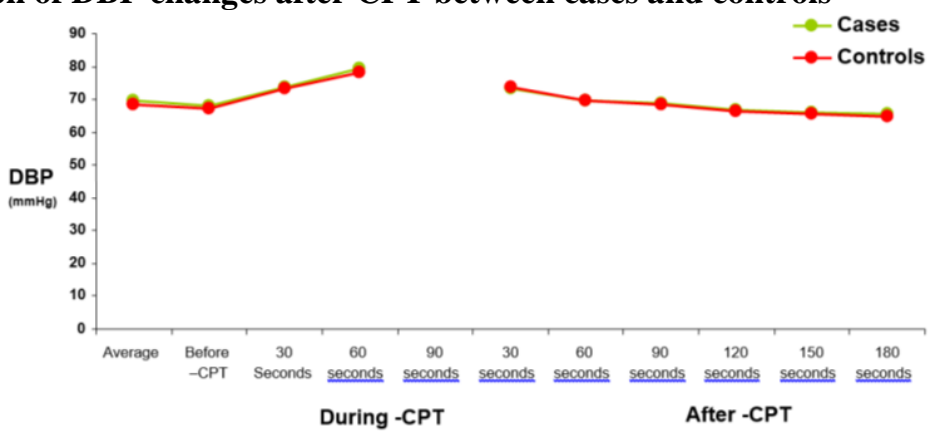

The mean and standard deviation (SD) of age, anthropometric variables and their comparison between cases and controls are depicted in Table 1. Both the groups were comparable for age and anthropometric measurements. Diabetic family history among cases showed that about $40 \%$ had paternal and $30 \%$ had maternal. Among parental history, paternal positive history predominates than maternal.

The comparison of heart rate before, during and after Cold Pressor test, between cases and controls has been depicted in Table 2. The basal heart rate before beginning of CPT was comparable between the two groups $($ Cases $=74.40 \pm 8.02 \mathrm{bpm}$, Controls $=$ $75.63 \pm 6.09 \mathrm{bpm}, \mathrm{P}=0.444$ ). The heart rate during CPT was comparable between the two groups. At $30 \mathrm{sec}$ HR was $78.70 \pm 7.33 \mathrm{bpm}$ and $80.93 \pm 6.69 \mathrm{bpm}(\mathrm{P}=0.160)$ and by $60 \mathrm{sec}$ it reached $81.35 \pm 8.44 \mathrm{bpm}$ and $83.35 \pm 7.67 \mathrm{bpm}(\mathrm{P}=0.271)$ in cases and controls . The normal response to CPT is increase in HR by $7-12$ beats/min. In the study both cases and controls showed difference of about 7 beats $/ \mathrm{min}$ and 8 beats $/ \mathrm{min}$ respectively, which is a normal response. However, HR response to post CPT showed significant differences between two groups across all the time points. Controls showed higher HR than cases at all the time points in Graph.1. However, the reduction of HR with time was more gradual in controls. Whereas, cases showed an abrupt reduction of heart rate at the $30 \mathrm{sec}$ which maintained later.

The systolic and diastolic blood pressure response to CPT is given in Table 3 and Table 4 respectively. Normally during CPT the SBP increases by $10-20 \mathrm{~mm}$ of $\mathrm{Hg}$ and DBP increases by $8-10 \mathrm{~mm}$ of $\mathrm{Hg}$. The SBP during CPT was comparable between the two groups. At $30 \mathrm{sec}$ SBP was $112.35 \pm 9.12 \mathrm{~mm}$ of $\mathrm{Hg}$ and $110.55 \pm 7.64 \mathrm{~mm}$ of $\mathrm{Hg}(\mathrm{P}=0.342)$ and by $60 \mathrm{sec}$ it reached $118.63 \pm 8.41 \mathrm{~mm}$ of $\mathrm{Hg}$ and $117.18 \pm 7.61 \mathrm{~mm}$ of $\mathrm{Hg}(\mathrm{P}=0.421)$ in cases and controls. The DBP during CPT was comparable between the two groups. At $30 \mathrm{sec}$ DBP was $73.78 \pm 6.76 \mathrm{~mm}$ of $\mathrm{Hg}$ and $73.20 \pm 6.34 \mathrm{~mm}$ of $\mathrm{Hg}(\mathrm{P}=0.696)$ and by $60 \mathrm{sec}$ it reached $79.48 \pm 9.05 \mathrm{~mm}$ of $\mathrm{Hg}$ and $78.15 \pm 8.76 \mathrm{~mm}$ of $\mathrm{Hg}(\mathrm{P}=0.508)$ in cases and controls. But, the post CPT changes in either of blood pressure did not demonstrate any significant differences. However, the graphical representation of SBP changes after CPT (Graph 2) shows fluctuation among cases before it reaches the stable value, whereas, in controls the decrease was at constant level. Even though the absolute values were not much significant the dynamics of physiological response among cases give an insight to cardiovascular regulation among offspring of T2DM. The graphical representation of DBP changes after CPT is shown in Graph 3.

\section{Discussion}

The hypothesis is that autonomic status and its reactivity to physical stress is heightened and sustained in offspring with parental history of diabetes. The present study intends to evaluate the autonomic status and its reactivity among healthy offspring with parental history of diabetes and compare the same with age and gender matched offspring without parental history of diabetes. Here we have attempted to assess the changes in the cardiac autonomic activity and its reactivity to cold stress among the healthy offspring of diabetics; which if present may act as warning bells of future diabetes, among healthy offspring with parental history of T2DM.

Dysfunction in the autonomic nervous system activity is associated with increased risk of developing diabetes in future and therefore it may serve as a predicting factor in early detection of diabetes risk among the population. ${ }^{[10,11]}$ The reactivity hypothesis has suggested that exaggerated response and the dynamics of physiological recovery to the stressor may predict the development of cardiovascular diseases in future and any deviation from the normal recovery could be the earliest subclinical sign. Autonomic reactivity to a challenge like that of cold offers a greater scope to evaluate and assess the capability of autonomic system to regulate and maintain homeostasis. ${ }^{12-14}$

The cold presser response is an indicator of sympathetic activity after cold stress. The cold Pressor test (CPT) triggers in healthy subjects a vascular sympathetic activation and increase in blood pressure. This may be due to an increased $\mathrm{CO}$ during the initial period of the test with little increase in muscle sympathetic nerve activity; while an increase in this 
activity elevates peripheral resistances in the later period. $^{15}$

Studies have shown variable response of HR and BP during CPT among healthy adults. There can be an initial rise and consistent increase in HR or HR may rise initially and reduce subsequently. This variation in response is attributed to interplay between cardiac sympathetic and parasympathetic innervations. In the present study subjects of both groups showed an increase in HR in CPT which infers that there was an increase in cardiac sympathetic activation. However, the interesting observation was the HR response during recovery after CPT. The controls demonstrated attenuation of HR which was gradual an at a constant rate whereas in offspring of diabetics there was abrupt reduction of heart rate during first minute after CPT. So this information provides a greater insight the way cardiac autonomic activity responds to a stressor. Whereas, such a response of blood pressure was not observed among cases. Both SBP and DBP after CPT recovered in the same phase in both the groups. So in the present study even though heart rate response to recovery after CPT was within normal limits but the projector of response seems to be more acute, abrupt and deviated among cases as compared to controls.

\section{Conclusion}

In the present study the HR response to CPT was comparable, but after CPT the recovery of HR was smooth and gradual in the controls, whereas it was abrupt in cases and was maintained thereafter and the graphical representation of SBP changes after CPT shows fluctuation among cases before it reaches the stable value, whereas, in controls the decrease was at constant level. This as a whole signifies altered autonomic reactivity to physical stress among the offspring with parental history of T2DM when compared to their counterparts and hence this points towards the fact that they are at a risk of developing future autonomic dysfunction and cardiovascular complications.

\section{References}

1. Sahay BK. Diabetes Mellitus- Basic consideration. In: Shah SN, editor. API text book of medicine. $8^{\text {th }}$ ed. Mumbai (India): The association of physician of India; 2008. P. 1042-72.

2. Ramachandran A and Snehalatha C. Type 2 Diabetes Mellitus - The Epidemic Of The 21st Century: The Indian Scenario. NT. J. DIAB 1999;19:158.

3. Sladek R, Rocheleau G, Rung J, Dina C, Shen L, et al. A genome-wide association study identifies novel risk loci for type 2 diabetes. Nature. 2007;445:881-5.

4. Pfeifer MA, Weinberg CR, Cook DL, Reenan A, Halter JB, Ensinck JW, Porte D Jr: Autonomic neural dysfunction in recently diagnosed diabetic subjects. Diabetes Care, 1984;7:447-53.
5. Lehtinen JM, Uusitupa M, Siitonen O, Pyo“ ra“la“ K: Prevalence of neuropathy in newly diagnosed NIDDM and nondiabetic control subjects. Diabetes, 1989;38:1307- 13 .

6. Nonogaki K: New insights into sympathetic regulation of glucose and fat metabolism. Diabetologia,2000;43:53349.

7. Shimazu T: Innervation of the liver and glucoregulation: the role of the hypothalamus and autonomic nerves. Nutrition, 1996;12:65-6.

8. Reaven GM, Lithell H, Landsberg L: Hypertension and associated metabolic abnormalities: the role of insulin resistance and the sympathoadrenal system. $N$ Engl J Med,1996;334:374-82.

9. Carnethon MR, Golden SH, Folsom AR, Haskell W, Liao D: Prospective investigation of autonomic nervous system function and the development of type 2 diabetes: the Atherosclerosis Risk in Communities study, 19871998. Circulation, 2003;107:2190-5.

10. Frontoni S, Bracaglia D, Baroni A, Pellegrini F, Perna M, Cicconetti E, et al." Early Autonomic Dysfunction in Glucose-Tolerant but Insulin-Resistant Offspring of Type 2 Diabetic Patients". Hypertension. 2003;41:1223-7

11. Carnethon MR, Jacobs DR, Sidney S, Liu K. "Influence of Autonomic Nervous System Dysfunction on the Development of Type 2 Diabetes". Diabetes Care 26:3035-41,2003

12. Nageswari KS, Sharma R, Kohli DR. Assessment of respiratory and sympathetic cardiovascular parameters in diabetic and obese school children. Indian J Physiol Pharmacol 2007;51:235-43.

13. Valensi P, Bich Ngoc PT, Idriss S, Paries J, Cazes P, Lormeau B, et al. Haemodynamic response to an isometric exercise test in obese patients: Influence of autonomic dysfunction. International Journal of Obesity 1999;23:543-9.

14. Diwan SK, Jaiswal N, Wanjari AK, Mahajan SN. Blood pressure response to Treadmill testing among Medical graduates: The Right time to Intervene. Indian Heart Journal 2005;57:237-40.

15. Victor RG, Leimbach WN, Seals DR, Wallin BG, Mark AL Effects of the cold Pressor test on muscle sympathetic nerve activity in humans. Hypertension 1987;9:429-36. 